\title{
Role of Emergency Medical Services in pre-hospital Management of Road Accidents, appropriate on-site Actions.
}

\author{
Isuf Bajrami *, Milazim Gjocaj, Blerim Krasniqi
}

Received: 03 August 2021 / Accepted: 30 August 2021 / Published online: 20 January 2022

This article is published with open access at https://journal.astes.org.al

(C) The author(s) 2022. \& Copyright (C) 2022, the Albanian Society for Trauma and Emergency Surgery

(c) The Albanian Journal of Trauma and Emergency Surgery is an Open Access Journal. All articles are distributed under the terms of the Creative Commons Attribution Non-Commercial License: http://creativecommons.org/licenses/by-nc/4.0/) which permits unrestricted non-commercial use, distribution, and reproduction in any medium provided the original work is properly cited.

\begin{abstract}
Introduction: Around 1.250000 people die each year due to traffic accidents. Traffic accident injuries are the leading cause of death in the most productive age group - 20-45 years old. 20 to 50 million people end up with injuries, disability because of traffic accident injuries.

Purpose of study: To identify the most common factors of traffic accidents. To compare the number of accidents and casualties at local, regional and global level. To evaluate the way traffic accidents are handled from urgent medicine services and the Emergency Medical Center (EMC) in particular.

To improve the quality of management traffic accident from medical teams.

Material and methods: data for this paper is extracted from EMC and archive protocols in different years, carrying out data analysis. We have cooperated with EMC of University Clinical Center of Kosovo (UCCK), and Kosovo Police - Pristina regional unit. Retrospective method of research and afterwards descriptive and analytical method has been applied.

Results: According to Police statistics, the largest number of accidents in traffic in Kosovo.

The EMC in Pristina had 1024 traffic accident interventions in 2019 but 2020 the traffic accidents are lowest for 181 accidents, because we have the decrease in circulation as a result of the CIVID pandemic 19. The largest number was in August - 198 cases $(15.4 \%)$ while the lowest number was in May - 69 (5.4\%). Of 604 cases of traffic accidents that have been analyzed, 212 or $35.1 \%$ included persons of age group 16-25. Of the total number, 411 or $68.04 \%$ were males and 193 or 31,9\% were females.

Conclusion: The main factor of traffic accidents remains human factor. Traffic accidents increase the incidence of death and disability in general population.

Enforcing Emergent Medical Services, promoting and educating the population, institutional cooperating, have positive impact in reducing the number of traffic accident, decreasing mortality and disability caused by traffic accidents.

Proposal of measures: organizing seminars in national level for young people in order to increase the awareness about dangers in traffic, educating children in kindergartens, elementary schools and high schools...

Key words: traffic accident, medical urgency, fatality,
\end{abstract}

\section{Introduction}

Around 1.250000 people die each year due to traffic accidents. Injuries to the human body in traffic accidents

Original article, no submission or publication in advance or in parallel

\section{* Corresponding author: \\ Isuf Bajrami MD}

$\bowtie$ isufbajrami@gmail.com

Faculty of Medical Sciences "Rezonanca”, Centre of Emergency Medicine, Pristina, Kosovo are of particular importance as they usually occur away from health institutions. In these situations, the lives of people injured in an accident often depend on the people who are involved in traffic, on their knowledge, availability and willingness to provide basic or basic assistance. $[1,2]$ About 1.25 million people die each year as a result of traffic accidents. Road traffic injuries are the leading cause of death at the most productive age of 20-45 years. [3-5] Between 20 and 50 million people end up with injuries, disabilities as a result of injuries sustained during the accident.

Half of those who die in road accidents are "active participants in traffic": pedestrians, cyclists and motorcyclists. If no precautions are taken, it is expected that 
by 2030 road traffic accidents will be ranked seventh in the list of leading causes of death. [6-8]

Purpose of study is: to show the role and importance of mobile emergency teams in providing professional assistance at the scene in traffic accidents; to present the situation with statistical data, at the same time to influence the decision-making institutions in improving this situation; to show the importance of cooperation with the Police, Firefighters, Central and local level institutions, educational-scientific institutions, etc.; to present the results and principles of the work of Emergency Medical Center (EMC), during the treatment of the injured. [4]

\section{Materials and methods}

Collection and comparison of statistical data related to road traffic accidents to reflect the problem, in the EMC of Pristina for a different period of time 2017-2020.

Identification of the most frequent factors of road traffic accidents. Comparison of the number of accidents and victims at the country, region and world level.

Evaluation regarding the way of managing road traffic accidents by emergency services with special emphasis on cases of interventions by the EMC. Improving the quality of treatment in road traffic accident management by EMC teams.

\section{Results and Discussions:}

Elementary actions: in traffic accidents, the Emergency Medical Service (EMS) must be notified as soon as possible (tel.194 or 112; and Police tel.192 or 112).

If the accident occurs on road axes outside the settlements, where there is no telephone access, this action is performed through traffic participants with mobile phones.

Sometimes rescue is possible only with special teams, with the help of necessary technical means such as the Fire Service (tel.193).

Actions on site; Secure the crash site from vehicles circulating through the safety triangle at a sufficient distance. The distance to the road outside the settlements must not be less than 100 meters. In cases of image reduction, the flashing light or fire signal is set. (tab.7)
Actions in the vehicle; Disconnect the engine of the damaged vehicle, pull the contact key and connect the battery, brake the vehicle or place any braking device between the wheels. In case of fire in the vehicle, chemical extinguishing should be started immediately. Passengers must first be released from the burning vehicle. If the traveler has a flare, he should be extinguished, preferably by the dry method: the person with the flame should be covered with a blanket, clothes, then he should lie on the ground, with his hands slowly and carefully hit the cover on the lit parts. If the body clothes are burnt, they should be removed immediately, although in case of their removal difficulties are encountered.

We turn off with water only if we have the source close and in sufficient quantities.

Cooperation with the Police consisted of;

- The police must be notified immediately through the number (tel. 192 or 112), the data on the place of the accident, the number of injured and the types of injuries are provided.

- If the witnesses of the accident for any reason have left the place of the accident, their names, address and license plate number must be indicated.

- If any vehicle of the injured or dead person is removed from the place of disaster, this place should be marked with chalk, stones, etc.

- Alcoholic beverages should not be given even in the smallest quantities to the injured or to other participants in the accident, as this action would make it difficult to determine criminal responsibility.

Call to the dispatch center was reached by;

The person who reports to the dispatch center of EMS, must be willing and calm to provide this information. (tab.6)

1. Short case description e.g., traffic accident, number of injured and nature of injuries, etc.

2. Number of persons seeking emergency assistance.

3. Brief description of the condition of the sick, injured or injured. [5-6]

4. The type of assistance that should be provided to the injured, injured, description of the injury, briefly, for example, open or closed wound on the head of the extremities, accident from alcohol intoxication, drugs, etc. (tab.1, 2, 3, 4, 5) 
Table 1. Structure of accidents in Kosovo for the period 2017/2018

\begin{tabular}{|l|c|c|c|c|c|c|}
\hline & \multicolumn{2}{|c|}{ Year 2017 } & \multicolumn{2}{c|}{ Year 2018 } & \multicolumn{2}{c|}{ Total } \\
\hline Types of accidents & No. of cases & $\mathbf{\%}$ & No. of cases & $\mathbf{\%}$ & No. of cases & \% \\
\hline Fatal accidents & 122 & 54 & 100 & 46 & 222 & 100 \\
\hline Dead persons & 137 & 51 & 129 & 49 & 266 & 100 \\
\hline Accidents with injuries & 6390 & 50.68 & 6217 & 49.32 & 12607 & 100 \\
\hline Injured persons & 12645 & 50.57 & 12359 & 49.43 & 25004 & 100 \\
\hline Damage accidents & 11183 & 54.27 & 9424 & 45.63 & 20607 & 100 \\
\hline Total & $\mathbf{1 7 6 9 5}$ & $\mathbf{5 2 . 9 2}$ & $\mathbf{1 5 7 4 1}$ & $\mathbf{4 7 . 0 8}$ & $\mathbf{3 3 4 3 6}$ & $\mathbf{1 0 0}$ \\
\hline
\end{tabular}

Table 2. Comparison of accidents in Kosovo for January-December 2018/2019

\begin{tabular}{|c|c|c|c|c|c|c|}
\hline & \multicolumn{2}{|c|}{ January-December 2018} & \multicolumn{2}{|c|}{ January - December 2019} & \multicolumn{2}{|l|}{ Total } \\
\hline Type of accident & No. of cases & $\%$ & No. of cases & $\%$ & $(+/-)$ & $\%$ \\
\hline Fatal accidents & 100 & 0.63 & 100 & 0.62 & 0 & 0.00 \\
\hline Dead persons & 129 & 0.71 & 113 & 0.69 & -16 & -12.40 \\
\hline Accidents with injuries & 6217 & 39.5 & 6140 & 37.9 & -77 & -1.24 \\
\hline Injured persons & 12359 & 78.5 & 1865 & 73.2 & -494 & -4.00 \\
\hline Damage accidents & 9424 & 59.9 & 9959 & 61.5 & +535 & +5.68 \\
\hline Total & 15741 & & 16199 & & +458 & 45634 \\
\hline
\end{tabular}

Source: Ministry of Internal Affairs, Kosovo Police. General Police Directorate (Updated:10.01.2020)

Table 3. Comparison of accidents in Kosovo for January-December 2019/2020

\begin{tabular}{|l|c|c|c|c|c|c|}
\hline & \multicolumn{2}{|l|}{ January - December 2019 } & \multicolumn{2}{l|}{ January - December 2020 } & \multicolumn{2}{l|}{ Total } \\
\hline Type of accident & No. of cases & $\mathbf{\%}$ & No. of cases & \% & $(+/-)$ & $\%$ \\
\hline Fatal accidents & 100 & 0.62 & 76 & 0.54 & -24 & -24.00 \\
\hline Dead persons & $\mathbf{1 1 3}$ & $\mathbf{0 . 7 1}$ & $\mathbf{8 1}$ & $\mathbf{0 . 5 8}$ & -32 & -28 \\
\hline Accidents with injuries & 6140 & 37.9 & 5396 & 38.9 & -744 & -12.12 \\
\hline Injured persons & 12359 & 78.5 & 1865 & 73.2 & -494 & -4.00 \\
\hline Damage accidents & 9959 & 61.5 & 8375 & 60.5 & -1584 & -15.91 \\
\hline Total & $\mathbf{1 6 1 9 9}$ & & $\mathbf{1 3 8 4 6}$ & $\mathbf{- 2 3 5 2}$ & & -14.52 \\
\hline
\end{tabular}

Table 4. Overview of deaths in road accidents, in the country, region and beyond

\begin{tabular}{|l|c|c|}
\hline States & The death toll per in 2017 & Number of dead per100,000 inhabitants \\
\hline Bosnia and Herzegovina & 633 & 12.65 \\
\hline Albania & 395 & 12.32 \\
\hline Monte Negro & - & 9.01 \\
\hline Turkey & 6954 & 8.85 \\
\hline Croatia & 391 & 8.22 \\
\hline Kosovo & 137 & 7.8 \\
\hline Northern Macedonia & 169 & 7.02 \\
\hline Greece & 890 & 7.0 \\
\hline Serbia & - & 6.38 \\
\hline Slovenia & - & 5.75 \\
\hline
\end{tabular}

Statistics are taken from http://www.worldlifeexpectancy.com/road-traffic-accidents 
Table 5. Number of interventions in traffic accidents by months during the calendar year 2017, 2018, 2019, 2020

\begin{tabular}{|l|c|c|c|c|c|c|c|c|}
\hline & \multicolumn{2}{|c|}{ Year 2017 } & \multicolumn{2}{l}{ Year 2018 } & \multicolumn{2}{l|}{ Year 2019 } & \multicolumn{2}{c|}{ Year 2020 } \\
\hline Months & No. & $\%$ & No. & $\%$ & No. & $\%$ & No. & $\%$ \\
\hline January & 85 & 7.40 & 101 & 7.9 & 74 & 7.2 & 68 & 8.0 \\
\hline February & 80 & 6.90 & 83 & 6.4 & 95 & 9.2 & 75 & 8.8 \\
\hline March & 83 & 7.20 & 69 & 5.4 & 76 & 7.4 & 58 & 6.8 \\
\hline Aprill & 85 & 7.40 & 108 & 8.4 & 66 & 6.4 & 33 & 3.9 \\
\hline May & 109 & 9.50 & 98 & 7.6 & 87 & 8.5 & 47 & 5.5 \\
\hline June & 118 & 10.20 & 116 & 9.1 & 92 & 8.9 & 77 & 9.1 \\
\hline July & 114 & 9.90 & 110 & 8.6 & 84 & 8.2 & 92 & 10.9 \\
\hline August & 95 & 8.20 & 198 & 15.4 & 114 & 11.1 & 67 & 7.9 \\
\hline September & 133 & 11.50 & 101 & 7.9 & 81 & 8.0 & 89 & 10.5 \\
\hline October & 98 & 8.50 & 121 & 9.4 & 88 & 8.6 & 92 & 10.9 \\
\hline November & 89 & 7.70 & 95 & 7.4 & 83 & 8.1 & 60 & 7.1 \\
\hline December & 94 & 8.20 & 83 & 6.5 & 84 & 8.2 & 85 & 10.0 \\
\hline Total & $\mathbf{1 1 5 3}$ & $\mathbf{1 0 0 . 0}$ & $\mathbf{1 2 8 3}$ & $\mathbf{1 0 0}$ & $\mathbf{1 0 2 4}$ & $\mathbf{1 0 0}$ & $\mathbf{8 4 3}$ & $\mathbf{1 0 0}$ \\
\hline
\end{tabular}

Table 6. Number of accident patients. in traffic handled by EMC teams for 2018 according to gender and age.

\begin{tabular}{|c|c|c|c|c|c|c|}
\hline Age group & \multicolumn{2}{|c|}{ Male } & \multicolumn{2}{c|}{ Females } & \multicolumn{2}{c|}{ Total } \\
\hline & No. of cases & $\%$ & No. of cases & $\%$ & No. of cases & $\%$ \\
\hline $\mathbf{1 6}-\mathbf{2 5}$ years old & $\mathbf{1 4 7}$ & $\mathbf{3 5 . 8}$ & $\mathbf{6 5}$ & $\mathbf{3 3 . 7}$ & $\mathbf{2 1 2}$ & 35.1 \\
\hline $\mathbf{2 6}-35$ years old & 94 & 22.9 & 37 & 19.2 & 131 & 21.7 \\
\hline $\mathbf{3 6 - 4 5}$ years old & 62 & 15.1 & 39 & 20.2 & 101 & 16.7 \\
\hline $\mathbf{4 6 - 5 5}$ years old & 46 & 11.2 & 29 & 15.0 & 75 & 12.4 \\
\hline $\mathbf{5 5 - 6 5}$ years old & 33 & 8.1 & 16 & 8.3 & 49 & 8.1 \\
\hline$>\mathbf{6 5}$ years old & 16 & 3.9 & 7 & 3.6 & 23 & 3.8 \\
\hline Total & $\mathbf{4 1 1}$ & $\mathbf{6 8 . 0 4}$ & $\mathbf{1 9 3}$ & $\mathbf{3 1 . 9}$ & $\mathbf{6 0 4}$ & $\mathbf{1 0 0}$ \\
\hline
\end{tabular}

Number of patients injured in traffic treated by EMC Pristina teams for 2018 by age and gender groups.

Out of a total of 604 cases, the age group 16-25 dominated with 212 cases or $35.1 \%$. (tab.6)

Out of the total number 604, males dominated with 411 cases or $68.04 \%$, while females had 193 cases or $31.9 \%$.

\section{Conclusions}

The main factor of road traffic accidents is the human factor. Road traffic accidents increase the incidence of death and disability in the population. Laws and their implementation, technical condition of vehicles, road infrastructure is also identified factors that affect the increase in the number of accidents in road traffic. Promotion and education of the population institutional cooperation reduces the number of road traffic accidents and their consequences.

Preventive measures; Compilation of the State Strategy for Road Traffic Safety in Kosovo. This Strategy should include the modern management of road traffic accidents in several stages:

Before the accident - approval of laws, awareness programs (education), inter-institutional coordination 
Table 7. Number of services during the calendar year 2019, 2020

\begin{tabular}{|l|c|c|c|c|}
\hline & \multicolumn{2}{|c|}{ Year 2019 } & \multicolumn{2}{c|}{ Year 2020 } \\
\hline Types of services & No. of cases & \% & No. of cases & \% \\
\hline Field interventions & 16083 & 42 & 14410 & 68.5 \\
\hline Admission-triage visit & 6957 & 18 & 560 & 2.66 \\
\hline Minor surgery & 367 & 1.0 & 39 & 0.18 \\
\hline Reanimation & 183 & 0.5 & 65 & 0.30 \\
\hline Semi-intense & 3003 & 8.0 & 269 & 1.27 \\
\hline Interventions & 1964 & 5.2 & 181 & 1.5 \\
\hline Traffic accidents & 1024 & 2.7 & 843 & 7.0 \\
\hline Field disaster & 738 & 2.0 & 678 & 5.6 \\
\hline Laboratory & 1747 & 4.6 & 151 & 1.25 \\
\hline ECG & 967 & 2.5 & 420 & 3.49 \\
\hline Transports & 3983 & 11 & 2697 & 22.4 \\
\hline Death findings & 620 & 1.6 & 703 & 5.85 \\
\hline \multicolumn{1}{|c|}{ Total: } & $\mathbf{3 7 6 3 6}$ & $\mathbf{1 0 0}$ & $\mathbf{2 1 0 1 6}$ & $\mathbf{1 0 0}$ \\
\hline
\end{tabular}

(police, education, Red Cross, health, community, etc.), equipping with working tools (communication, transportation). [10]

High fines set by new law on road traffic rules seem to have given first results in reducing accidents in Kosovo. This stage must be carried out continuously.

During the accident-giving first aid by the injured (among themselves) and the surrounding population (this only succeeds if the first stage is well done).

Rapid and coordinated response of specialized medical and police emergency teams. Atention! Appreciate life! Accidents do not happen, they are caused! [8,9]

Acknowledgement; We would like to thank medical staff of EMC of the University Clinical Center of Kosovo.

Financial support and sponsorship: Nil.

Conflicts of interest: There are no conflicts of interest.

\section{References}

1. AAOS Emergency Care and Transportation of the Sick and Injured, Editor Andrew N.Pollak, Boston, Toronto, London, Singapure, 2011. Section 9; EMS Operations 1282. Chapter 36 Transport Operations 1330, Chapter 37 vehocle extraction and special RESCUE 1366. ISBN 978-1-448-1587-1

2. Alton Thygerson, Ed.D. Medical Writer, Benjamin Gulli, MD. Medical Editor. Jon R.Krohmer, MD, FACEP. Medical editor. AAOS First Aid Fifth Edition, Emergency Care and Safety Institute, CPR And ECG Guidelines. American College of Emergency Physicians, Jones and Bartlett Publishers. Sudbury, Masechusets. Boston, Toronto, London, Singapore. ISBN-13:978-0-7637-4244-7
3. Pirro Prifti, Anestezia, reanimacioni dhe ndihma e parë. Bot. i dytë. Shtsh. U.F.O. Press, Tiranë 2011. ISBN: 978-9928-12704-4

4. Peter T. Pons, MD, FACEP Editor, Norman E. McSwain, Jr..MD, FACS, NREMT-P, Editor -in -Chief, PHTLS; Will Chapleau, EMT-P,RN, TNS; Gregory Chapman, EMT-P, RRT, Asociate Editors. PREHOSPITAL TRAUMA LIFE SUPPORT Eight Edition. American College of Surgeons Committee Trauma, NAEMT. CHAPTER 5 Kinematiks of trauma.f.72-92.Chicago, Ilinois USA 2014, ISBN 978-1-28404173-6

5. Isuf Bajrami," Mjekësia Emergjente Paraspitalore “, Kolegji i SHM "Rezonanca " Prishtinë, 2016, Kapitulli 9, fq.339, 340, 341, 342. Tekst Univerz. ISBN 978-99518808-2-4

6. Isuf Bajrami, Ndihma urgjente mjekësore, Praktikum për veprime paraspitalore; bot. i Alma Mater Eurpea Campus College "REZONANCA" Shtsh. Lena Graphics Design, ISBN 978-9951-8968-4-9; Prishtinë 2020

7. Bajrami, I. (2020). Safety in Road Comunication and Role of Pre-Hospital Emergency Service. Albanian Journal of Trauma and Emergency Surgery, 4(1), 542-551. https://doi. org/10.32391/ajtes.v4i1.79

8. Christopher R.H. Newton Rahul K. Khare Urgentna Medicina, Brzi pregled, prevod Bojana Vukovic Banja Luka BOOK/ MARSO Beograd 2007. ISBN 978-99938-1-055-1

9. Ministria e Transportit dhe Post Telekomit të Kosovës, "Ligjet në komunikacionin rrugor" Prishtinë, 2007

10. Shërbimi Policor i Kosovës, "Memorandum Zyrtar",2014, http://www.worldlifeexpectancy.com/road-traffic-accidents; http://www.who.int/violence"http://www.who.int/violence injury_prevention/road_traffic/en/" 